\title{
Impact performance of FRC slabs under various strain rates
}

\author{
Alena Horska ${ }^{a}$, Pavel Jiricek, and Marek Foglar \\ CTU in Prague, Fac. Of Civil Engineering, Thákurova 7, 16629 Praha 6, Czech Republic
}

\begin{abstract}
Impact resistance of plain concrete and FRC composites gains high importance in the present days. This paper presents outcomes of the experiments focused on performance of FRC slabs subjected to impact loading of various strain rates. The FRC slabs, thickness 30,60 and $120 \mathrm{~mm}$ were subjected to various drop-weight impacts. The different drop-hammer weights provided different loading speeds and strain rates. The performance of the slabs was recorded with the use of high speed cameras. The cameras were used for impact speed control and specimen deflection measurement. With the use of the recordings, the force-time response of the slabs could be plotted. The plots correspond to the mechanical behaviour obtained by static load tests (loading speed $0.2 \mathrm{~mm} / \mathrm{min}$ ) but several differences can be found. Several types of FRC (varying fiber material, fiber content, etc.) were tested and evaluated. The experimental program is supplemented by numerical modelling which provides good agreement with the experimental results.
\end{abstract}

\section{Introduction}

Tensile resistance of concrete is significantly dependent on the speed of loading and type of reinforcement. The increase of strength of concrete subjected to loadings of higher strain rates is a well-known phenomenon and is described in the design standards [1,2] and literature, e.g. $[3,4]$. The dynamic increase factor (DIF) corresponds to the strain rate the concrete is subjected to and is used for quantification of the increase of tensile and/or compressive strength when describing the behaviour of concrete under extreme loadings such as blasts and impact. To obtain real values of impact resistance of the variously reinforced concrete samples, drop - weight experiments were performed.

A drop-weight frame was built for investigation of impact resistance of concrete and fiber reinforced cementitious composites. The device is as well used for investigation of fatigue loading on impact resistance.

\section{Experimental set up}

\subsection{Dropping device}

For the impact loading, a steel frame (Fig. 2a) carrying drop weight was built in the Experimental Centre of the CTU. The construction consists of a braced steel frame to ensure maximal stability of the dropping device. Due to laboratory build-in crane, height of the frame is limited to $4.1 \mathrm{~m}$. Horizontal base of the construction is made of a steel frame anchored to the floor of the laboratory. Vertical stability is provided by bracing diagonals. The frame was ordered, delivered and built in 2013, the drop weight and the hoist and burden in 2014. The burden is considered as a set of different weights to enable maximal variety of the drop-weight.

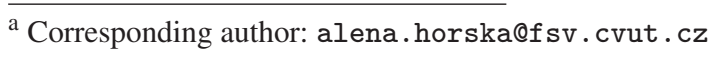
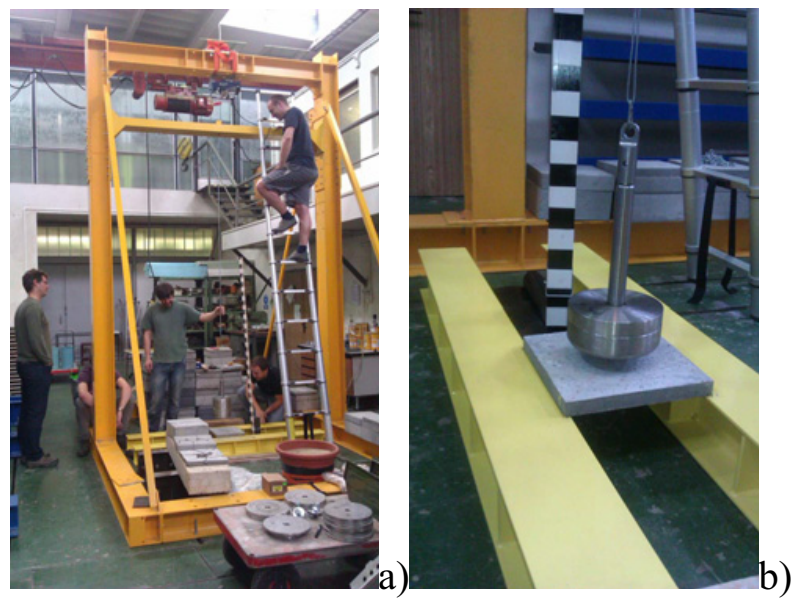

Figure 1. a) Steel frame with the hoist and the burden; b) Specimen support.

The tested concrete specimen is located in the biaxial centre of the horizontal frame. The sample is supported at two parallel sides by reinforced steel girders which were anchored to the floor (Fig. 1b). Lower surface of the specimen is $160 \mathrm{~mm}$ above the laboratory floor and is supported by flanges of the girders $15 \mathrm{~mm}$ on each side. The exact centre of the concrete sample under the burden was set up using a plummet.

The steel burden used during the experiment consisted of a central pole and a main cylinder/hammer, which supports steel discs of different weights (Fig. 2).

The required weight was obtained by combination of the steel discs. On the lower surface of the steel cylinder, a hemispherical tip $(\mathrm{R}=20 \mathrm{~mm})$ is placed, which concentrates the applied impact loading into one point (Fig. 3).

This is an Open Access article distributed under the terms of the Creative Commons Attribution License 4.0, which permits unrestricted use, distribution, and reproduction in any medium, provided the original work is properly cited. 


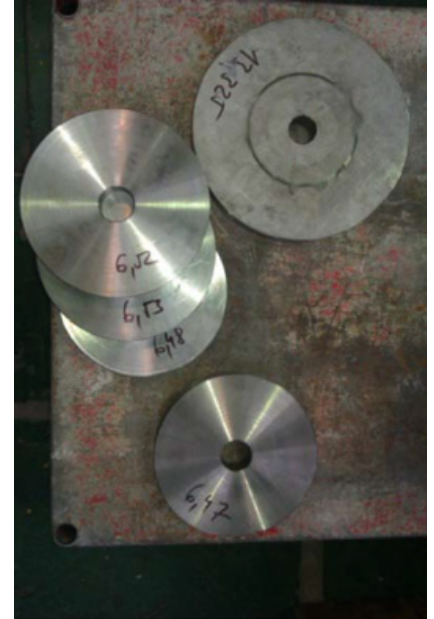

Figure 2. Steel discs of different weights.

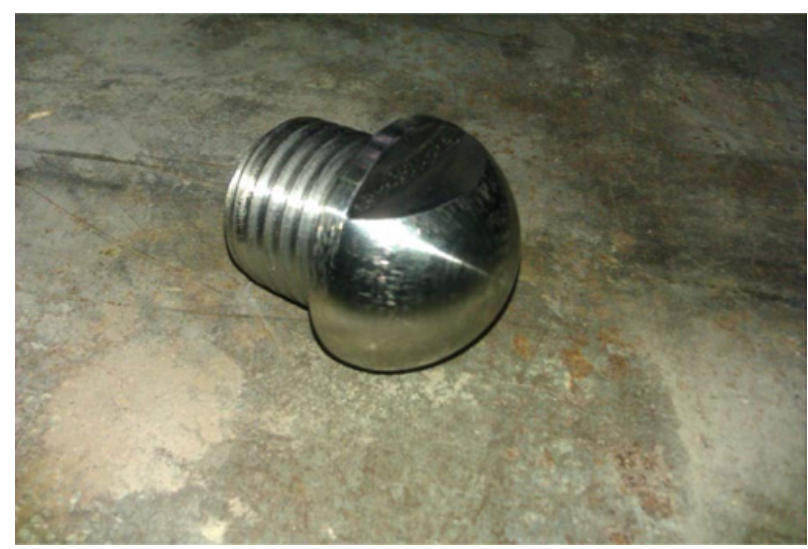

Figure 3. Hemispherical tip of the burden.

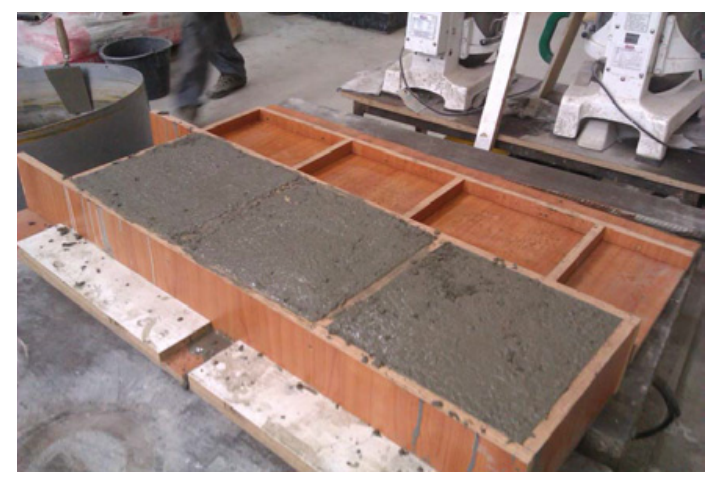

Figure 4. Concrete mixture in the forms.

\subsection{Tested specimens}

The specimens, loaded with the force impulse, were concrete tiles. Supplementary cubes used to determine compressive strength of evaluated concrete mixtures were cast. Tiles and cubes were cast in laboratories of Faculty of Civil Engineering. Dimensions of the tiles were $300 \times$ $300 \mathrm{~mm}$ with variable height $(30 / 60 / 120 \mathrm{~mm})$ (Fig. 4). The fibers used as reinforcement of several specimens were made of polypropylene $(54 \mathrm{~mm}$ long with tensile strength 570-660 MPa and steel $(60 \mathrm{~mm}$ long with tensile strength $1,115 \mathrm{MPa}$ for NSC and $13 \mathrm{~mm}$ long with tensile
Table 1. Tested concrete specimens.

\begin{tabular}{|l|l|l|l|}
\hline $\begin{array}{l}\text { Concrete } \\
\text { mixtures }\end{array}$ & Reinforcement & $\begin{array}{l}\text { Volume } \\
\text { of fibers }\end{array}$ & $\begin{array}{l}\text { Tested } \\
\text { (Feb 2015) }\end{array}$ \\
\hline NSC & - & - & YES \\
\hline NSC & PP & $9 \mathrm{~kg} / \mathrm{m}^{3}$ & YES \\
\hline NSC & FE & $80 \mathrm{~kg} / \mathrm{m}^{3}$ & YES \\
\hline NSC & PP & $4,5 \mathrm{~kg} / \mathrm{m}^{3}$ & NO \\
\hline NSC & FE & $40 \mathrm{~kg} / \mathrm{m}^{3}$ & NO \\
\hline NSC & TEX & - & NO \\
\hline NSC & TEX II & - & $\mathrm{NO}$ \\
\hline HPC 1 & FE & $100 \mathrm{~kg} / \mathrm{m}^{3}$ & NO \\
\hline HPC 1 & TEX & $100 \mathrm{~kg} / \mathrm{m}^{3}$ & NO \\
\hline HPC 1 & TEX II & $100 \mathrm{~kg} / \mathrm{m}^{3}$ & NO \\
\hline HPC2 & FE & $100 \mathrm{~kg} / \mathrm{m}^{3}$ & $\mathrm{NO}$ \\
\hline HPC2 & TEX & $100 \mathrm{~kg} / \mathrm{m}^{3}$ & NO \\
\hline HPC 2 & TEX II & $100 \mathrm{~kg} / \mathrm{m}^{3}$ & NO \\
\hline
\end{tabular}

TEX - basalt fabric - lower surface.

TEX II - basalt fabric - both surfaces.

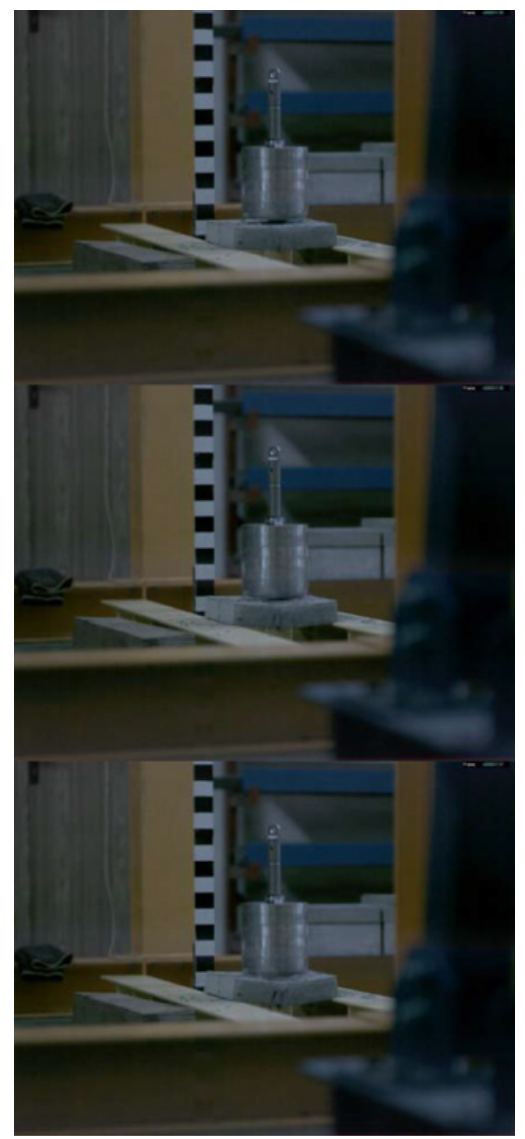

Figure 5. Impact process; $46.4 \mathrm{~kg}$ burden, $60 \mathrm{~mm}$ thick tile made of steel fiber reinforced concrete.

strength 2,750 MPa for HPC); a basalt fabric was used to reinforce some of the concrete tiles. The fabric was placed in two layers, lower surface and/or both surfaces. For each mixture, 3 identical specimens of all the used thicknesses were prepared (Table 1). Two of the specimens were loaded by different impact loading and one sample was used for three-point bending test.

In the first quarter of 2014 production of the burden and dropping device was ordered and production of 


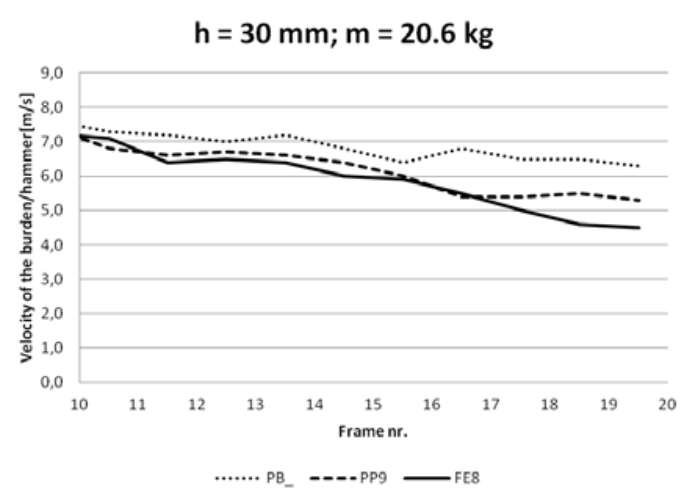

a)

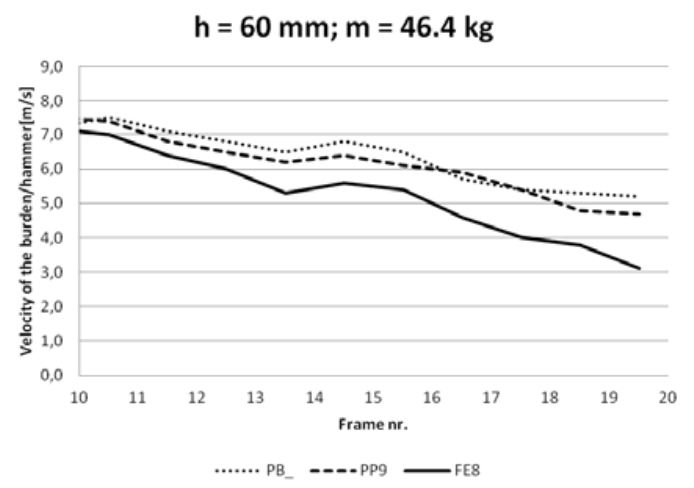

c)

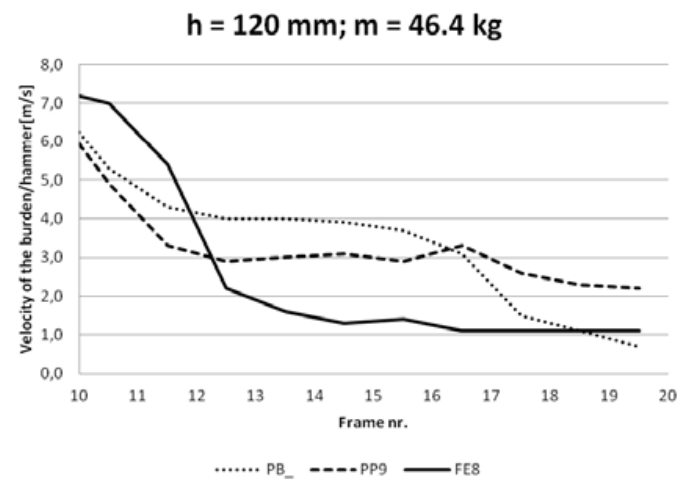

e)

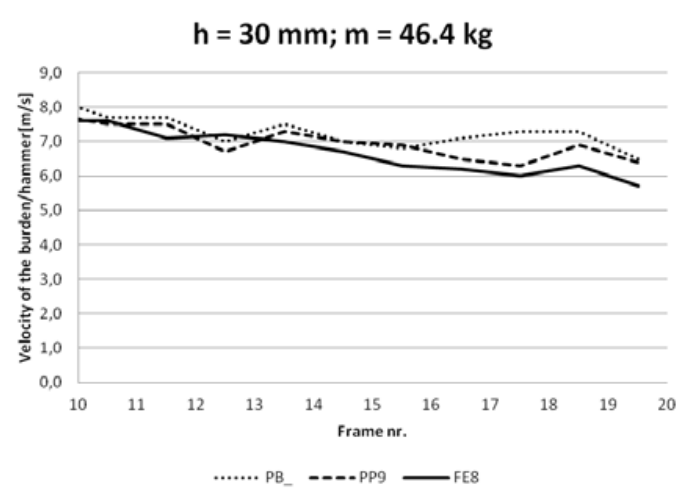

b)

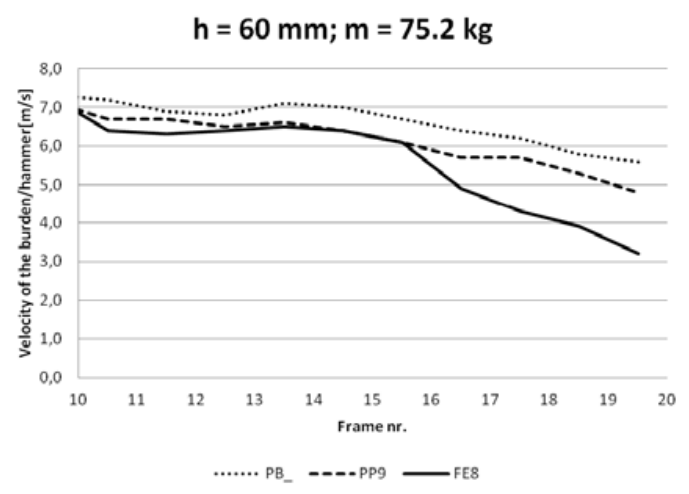

d)

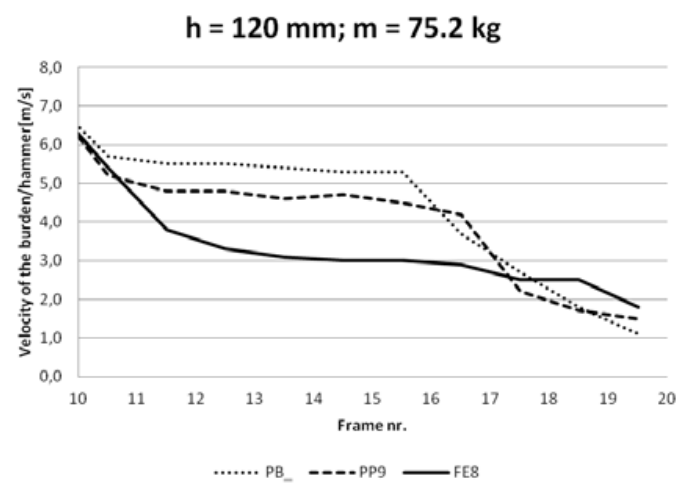

f)

Figure 6. Comparison of different material type with the same burden weight and the same thickness; a) Thickness $30 \mathrm{~mm}, 20.6 \mathrm{~kg}$ burden; b) Thickness $30 \mathrm{~mm}, 46.4 \mathrm{~kg}$ burden; c) Thickness $60 \mathrm{~mm}, 46,4 \mathrm{~kg}$ burden; d) Thickness $60 \mathrm{~mm}, 75.2 \mathrm{~kg}$ burden; e) Thickness $120 \mathrm{~mm}, 46.4 \mathrm{~kg}$ burden; f) Thickness $120 \mathrm{~mm}, 75.2 \mathrm{~kg}$ burden.

the concrete samples has begun. The production of the concrete tiles took almost half of the year; in total $117 \mathrm{pcs}$ of concrete tiles were cast. Each one of the specimens had to reach maximal compressive strength (min. 28 days).

\subsection{Recording of the experiments}

The release of the burden/hammer was recorded by a high speed camera. The camera was located $2-3 \mathrm{~m}$ from the specimen. To eliminate the effect of perspective, the horizontal level of the camera was set to the level of the tested specimen. The scale of the shots made by the camera was determined from the known height of the samples and from the lath with black and white stripes ( $50 \mathrm{~mm}$ wide). The camera was recording 1000-10000 fps.

The impact loading was recorded (Fig. 5), the captured decomposed frames were graphically processed. The velocity of the burden during impact and deflection of the sample were obtained and plotted in graphs.

\section{Evaluation}

To determine the impact resistance of specimens, the deceleration of the burden was observed (Fig. 6). According to known weight of the burden and height of the dropping device, the momentum was evaluated. From the change of the momentum (deceleration of the burden), 


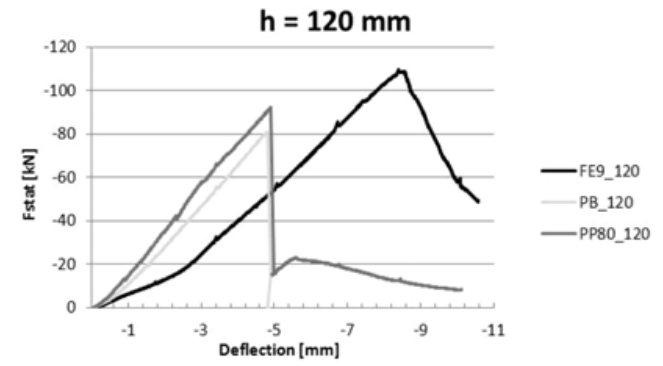

a)
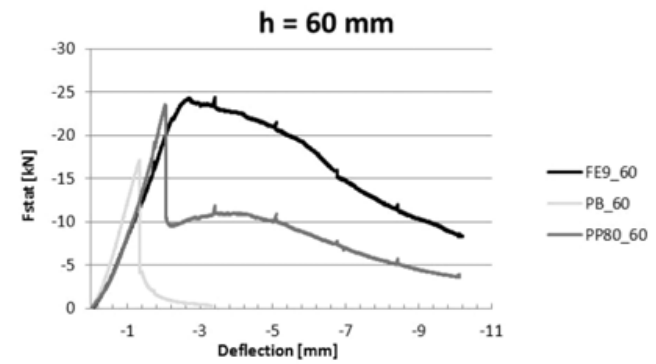

b)

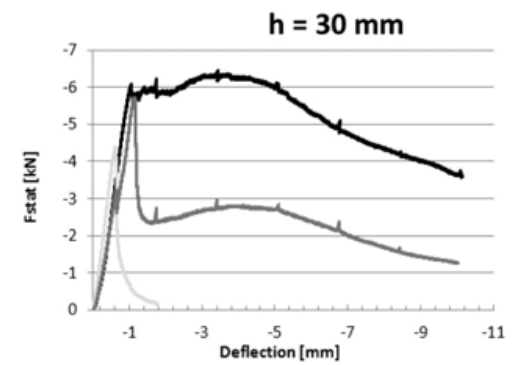

c)

Figure 7. Results of three-point bending test (speed of loading $0.2 \mathrm{~mm} / \mathrm{min}$ ); a) Specimens $120 \mathrm{~mm}$ thick; b) Specimens $60 \mathrm{~mm}$ thick; c) Specimens $30 \mathrm{~mm}$ thick.

the impact force leading to collapse of the specimen was determined.

In the graphs $\mathrm{PB}_{-}$refers to NSC mixture without reinforcement, PP9 to NSC with $9 \mathrm{~kg} / \mathrm{m}^{3}$ polypropylene fibers and FE8 to NSC with $80 \mathrm{~kg} / \mathrm{m}^{3}$ steel fibers.

The dynamic force required to break the specimen is simply obtained from the change of the velocity of the burden/hammer during impact.

$$
\begin{gathered}
F=m a \\
a=\Delta v / \Delta t .
\end{gathered}
$$

The results of three-point bending test are shown in Fig. 7 in graph plotting static force to deflection $(0.2 \mathrm{~mm} / \mathrm{min})$. Comparison of static and dynamic forces obtained from the experiment is presented in Table 2.

Fiber reinforced concrete (FRC) is a inhomogeneous material which mechanical properties can vary from specimen to specimen according to fiber content and distribution in the decisive cross-sections. In the presented experimental program, 3 specimens were cast of every concrete mix and specimen dimension. During probe experiments, the results showed only negligible variations, therefore the three specimens were used to study the effect

\begin{tabular}{|c|c|c|c|c|c|}
\hline $\begin{array}{l}\text { Concrete } \\
\text { mixtures }\end{array}$ & $\begin{array}{l}\mathbf{h} \\
{[\mathrm{mm}]}\end{array}$ & $\begin{array}{l}\text { Burden } \\
{[\mathrm{kg}]}\end{array}$ & $\begin{array}{l}\mathbf{F}_{\text {dyn }} \\
{[\mathrm{kN}]}\end{array}$ & $\begin{array}{l}\mathbf{F}_{\text {stat }} \\
{[\mathbf{k N}]}\end{array}$ & $\begin{array}{l}\mathbf{F}_{\text {dyn }} / \\
\mathbf{F}_{\text {stat }}\end{array}$ \\
\hline NSC & 30 & 20.6 & 5.2 & 4.4 & 1.18 \\
\hline NSC & 30 & 46.4 & 6.2 & 4.4 & 1.41 \\
\hline NSC & 60 & 46.4 & 15.5 & 17.2 & 0.90 \\
\hline NSC & 60 & 75.2 & 20.7 & 17.2 & 1.20 \\
\hline NSC & 120 & 46.4 & 74.2 & 81.0 & 0.92 \\
\hline NSC & 120 & 75.2 & 75.2 & 81.0 & 0.93 \\
\hline NSC-PP-9 & 30 & 20.6 & 6.9 & 5.7 & 1.21 \\
\hline NSC-PP-9 & 30 & 46.4 & 7.7 & 5.7 & 1.35 \\
\hline NSC-PP-9 & 60 & 46.4 & 23.2 & 23.5 & 0.99 \\
\hline NSC-PP-9 & 60 & 75.2 & 30.1 & 23.5 & 1.28 \\
\hline NSC-PP-9 & 120 & 46.4 & 116.0 & 92.2 & 1.26 \\
\hline NSC-PP-9 & 120 & 75.2 & 120.2 & 92.2 & 1.30 \\
\hline NSC-FE-80 & 30 & 20.6 & 8.2 & 6.5 & 1.26 \\
\hline NSC-FE-80 & 30 & 46.4 & 7.7 & 6.5 & 1.18 \\
\hline NSC-FE-80 & 60 & 46.4 & 23.2 & 24.5 & 0.95 \\
\hline NSC-FE-80 & 60 & 75.2 & 33.8 & 24.5 & 1.38 \\
\hline NSC-FE-80 & 120 & 46.4 & 102.1 & 109.0 & 0.94 \\
\hline NSC-FE-80 & 120 & 75.2 & 137.8 & 109.0 & 1.26 \\
\hline
\end{tabular}

Table 2. Comparison of static and dynamic strength.
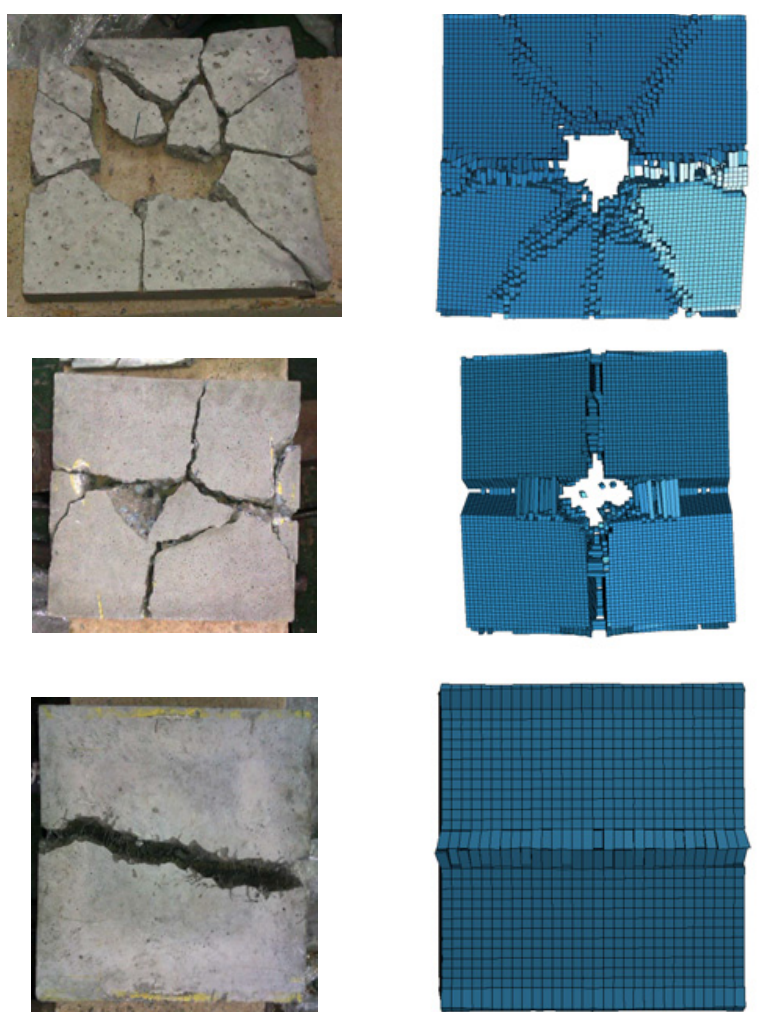

Figure 8. Illustrative comparison of the experiment and the numerical simulation.

of varying load on the performance of FRC subjected to impact loading.

\section{Numerical simulations}

Numerical simulations were prepared together with the experiment (Fig. 8), material models are calibrated according to the results of drop weight test. These results, together with results obtained from specimens not tested yet, will allow detailed description of behaviour 
of concrete under impact loading. Impact resistance of concrete reinforced with different types of fibers and basalt fabric will enable full-scale numerical simulations of extreme loading cases in civil engineering and increasing its impact resistance.

\section{Conclusions}

Concrete specimens reinforced with steel fibers slow the burden the most and plain concrete the least. The $30 \mathrm{~mm}$ thick tiles are the least impact resistant; on the other hand, the samples with height $120 \mathrm{~mm}$ almost stop the burden. The ratio of dynamic and static force needed to penetrate the element is 1.16 in average.

As a part of the experiment ongoing, numerical simulations were made to calibrate material model of normal strength concrete and different types of fiber reinforced concrete. Results of the simulation lead to good agreement with the experimental data.
The financial support of the Czech Science Foundation grant project 13-30441S is gratefully acknowledged.

\section{References}

[1] CEB-FIP Model Code 1990, Comité EuroInternational du Béton (1993).

[2] CEB-FIP Model Code 2010, Comité EuroInternational du Béton (2010).

[3] L. J. Malvar, C. A. Ross, ACI Material Journal, 95(6), 735-739 (1998).

[4] J. W. Tedesco, C. A. Ross, Journal of Pressure Vessel Technology, 120(4), 398-405 (1998).

[5] P. Jiřŕček, M. Foglar, Bridge Maintenance, Safety, manegement and Life Extension 2014, 762-768 (2014).

[6] P. Jiříček, M. Foglar, Proceeding of 23rd Military Aspects of Blast and Shock 2014 (2014). 